EXTENDED REPORT

\title{
Impact of an interdisciplinary low vision service on the quality of life of low vision patients
}

\author{
A Hinds, A Sinclair, J Park, A Suttie, H Paterson, M Macdonald
}

Br J Ophthalmol 2003;87:1391-1396

See end of article for authors' affiliations .....................

Correspondence to: Dr Alison Hinds, Chief Scientist Office, $\mathrm{St}$ Andrew's House, Regent Road, Edinburgh $\mathrm{EH} 1$ 3DG, UK; alison.hinds@ scotland.gsi.gov.uk

Accepted for publication 11 February 2002

\begin{abstract}
Aim: To investigate the impact of an interdisciplinary low vision service on the vision related quality of life of service users.

Methods: 71 patients were interviewed 2 weeks before their appointment with the service and again 6 months later to assess any changes in their vision related quality of life. The majority of these patients had age related macular degeneration.

Results: After contact with the service the majority of patients indicated a reduction in concern about most quality of life issues. They were significantly less anxious about deterioration of their vision, safety within the home, and coping with everyday life.

Conclusion: Improvements in many areas of their vision related quality of life indicate that this interdisciplinary low vision service has a positive impact on the lives of service users. However many patients were still unable to carry out their preferred everyday activities, and feelings of loneliness and isolation were unchanged. The identification of issues unrelieved by input from the service will be important in planning future service delivery.
\end{abstract}

$\mathrm{T}$ he scale of the low vision problem is considerable. There are estimated to be nearly one million visually impaired people in Britain, $90 \%$ of whom are over the age of 60 years. ${ }^{1}$ Serious sight loss can lead to depression, loneliness, and anxiety ${ }^{2}{ }^{3}$ and is an important risk factor for restriction in an older person's ability to carry out everyday activities. ${ }^{45}$ The most common causes of visual impairment in elderly people are age related macular degeneration (ARMD), cataract, and glaucoma. ${ }^{6}$

Approximately $85 \%$ of those known to be visually impaired have useful residual vision and could benefit from visual rehabilitation. ${ }^{17}$ Several studies have shown that visually impaired people can be helped to achieve some improvement in visual skills through a combination of clinical assessment, advice, and the prescription of low vision aids (LVAs), in conjunction with appropriate follow up and training. ${ }^{78}$ These different stages of care, however, are commonly fragmented, with those responsible for providing a clinical assessment of low vision and those involved in providing education, rehabilitation, and social work services functioning independently. ${ }^{9}$

A study undertaken to determine the type and location of low vision services within the United Kingdom concluded that in comparison with the probable number of people with a visual impairment in the United Kingdom, there are apparent inadequacies in terms of distribution, magnitude, and coordination of services. ${ }^{10}$ Recent reports have suggested that multidisciplinary models of low vision care offer considerable benefits to patients. ${ }^{11}$ A Royal College of Ophthalmologists publication in 1998 on the provision of low vision care also recommended multidisciplinary working. ${ }^{12}$

The interdisciplinary low vision service (ILVS) in this study was established in 1995 and is unique in the United Kingdom. Professionals from ophthalmology (associate specialist and staff grade), ophthalmic nursing, social work, and rehabilitation carry out joint assessments with patients and carers. An evaluation of the ILVS was undertaken in 1997 in order to investigate the benefits of interdisciplinary working practice and how such a service should be effectively managed. This study concluded that there were clear advantages of interdisciplinary working for staff, including shared knowledge and expertise and improved communication between professions, but that further study was required to assess the benefits of such a model to the service users. ${ }^{13}$

Throughout this study, the ILVS operated from two district general hospital low vision clinics. Patients who were referred to the clinics received a range of services tailored to their individual requirements. These included clinical assessment; diagnosis; referral for treatment; blind or partially sighted registration; refraction and prescription of LVAs, together with information, counselling, and support (Table 1). A rehabilitation worker or social worker shared the consultation with the ophthalmology staff at the low vision clinics and they also provided domiciliary follow up visits. There are close links with the low vision scheme provided by local community optometrists who see patients in their own locality, funded by the local health board. ${ }^{14}$ Approximately 500 patients are seen by the ILVS each year.

There has been a great deal of interest recently in quality of life (QOL) in relation to vision, ${ }^{15}$ particularly with respect to cataract surgery ${ }^{16}$ and glaucoma. ${ }^{17}$ Some studies investigating vision related QOL issues have employed generic QOL instruments which have been validated with low vision patients. ${ }^{18} 19$ However, it is unlikely that the full range of vision related problems can be adequately described within a general QOL framework as there are issues specifically related to vision. ${ }^{20}$

A variety of vision specific instruments have been developed to assess the impact of visual impairment on function and QOL. These include the Daily Living Tasks Dependent upon Vision (DLTV), ${ }^{21}$ the National Eye Institute Visual function questionnaire (NEI-VFQ), ${ }^{22}$ the Visual Function Index (VF-14), ${ }^{17}$ and the Vision-Related Quality of Life Questionnaire (VQOL). ${ }^{23}$ The VQOL, which has been employed in several outcome studies in the United Kingdom, including low vision rehabilitation ${ }^{24}$ and macular surgery, ${ }^{25}$ was selected as the most appropriate vision specific instrument for use in this study. It has been validated for use with ARMD patients, was relatively short and simple to 


\section{Table 1 Components of ILVS}

Patient history, visual assessment, LVA provision and initial training Examination and diagnosis Provision of information to patient and carer

Registration if appropriate Follow up phone call Domiciliary visit(s) addressing: independent living skills, mobility, LVA training, social benefits

Re-referral to LV clinic if necessary Social work/rehabilitation
Ophthalmic nurse and ophthalmologist Ophthalmologist Ophthalmic nurse and ophthalmologist, social work/ rehabilitation Ophthalmologist Social work/rehabilitation Social work/rehabilitation administer, and resulted in a total patient score which was useful for comparative purposes.

The VQOL consists of a core questionnaire with 10 broadly applicable items referring to physical, social, and psychological QOL issues identified by patients as being most important to them (VCMl). Each VCMl item is a 6 point ordinal scale which ranges from 0 (no problem) to 5 (extreme problem). The single index score which can be derived by taking the mean of the scores for individual items provides a global measure of concern about vision.

The VQOL was used in this study in conjunction with a "restrictions of daily living questionnaire" developed by researchers at the Manchester Royal Eye Hospital (MLVQ). ${ }^{24}{ }^{26}$ The MLVQ can be used to assess which of 19 different activities patients have attempted to perform over the past month, the degree of difficulty that they experienced in carrying out the task, and how important it was to them to be able to perform it.

\section{METHODS}

Ethical approval was granted by the local research ethics committee to carry out the study before its commencement.

All patients with appointments at either of the two low vision clinics between November 1998 and February 1999 were invited to participate in the study. Patients who had attended a low vision clinic during the previous 6 month period were excluded as were patients aged 16 years or less.

Patients were sent a letter in large print giving details of the study approximately 2 weeks before their appointment at the low vision clinic. An interviewer then contacted each patient by telephone to ask if they were willing to participate and if so, to arrange an interview in their home.

Patients who consented were interviewed in their own home 2 weeks before their ILVS clinic appointment. A total of 80 patients $(67 \%$ of those approached) agreed to be interviewed

Each patient completed a VCMI and MLVQ questionnaire in order to assess the impact of their visual impairment on vision related QOL and performance of activities of daily living. Participants also answered some general questions about their health and living arrangements over the past 6 months.

Six months after their appointment with the ILVS, 71 of the 80 patients $(89 \%)$ originally interviewed agreed to be reassessed. Of the remaining nine patients, two had died and seven were in poor health and were unable to be interviewed. Vision related QOL and restrictions in activities of daily living were measured using the VCMl and MLVQ. In addition, patients were asked if they had attempted to use any of the LVAs that they may have been prescribed for each of the tasks in the MLVQ and if so, how useful they had found the LVA for the task.

The questionnaires were analysed using dBaseIV and SPSS. Statistical tests used for comparing results from the

\section{Table 2 Diagnosis}

\begin{tabular}{lc}
\hline & No (\%) \\
\hline ARMD alone & $38(53)$ \\
ARMD + other diagnosis & $11(15)$ \\
Diabetic retinopathy & $9(13)$ \\
Glaucoma & $2(3)$ \\
Cataract & $2(3)$ \\
Retinitis pigmentosa & $2(3)$ \\
High myopia & $2(3)$ \\
Stroke & $2(3)$ \\
Other & $3(4)$ \\
Total & 71 \\
\hline
\end{tabular}

original study with the follow up study were the one way analysis of variance, Wilcoxon signed rank test, and the McNemar test.

\section{RESULTS}

The majority of participants recruited to the study were diagnosed with ARMD alone $(38,53 \%)$ or ARMD with an additional diagnosis (11, 15\%) (Table 2 ).

The majority of participants were 71 years of age or older $(55,78 \%)$ and approximately two thirds $(49,69 \%)$ were female (Table 3 ).

Fifty five $(78 \%)$ of the original cohort had not been seen previously by the ILVS (Table 3 ). Sixteen patients (22\%) had used the service on at least one occasion previously, although not within the 6 month period preceding their first interview for this study. Ten of the 16 patients $(62 \%)$ had not been seen for at least 1 year (Table 4).

Over half of the patients who participated in this study were living alone at the time of interview $(38,54 \%)$.

\section{ACTIVITIES OF DAILY LIVING}

The results of the MLVQ completed 2 weeks before contact with the ILVS and repeated 6 months later are summarised in Table 5.

There was a statistically significant increase in the number of patients who had read or tried to read ordinary print 6 months after their appointment with the low vision service compared with at their first interview. There was a significant decrease in the number of respondents who had read large print and shop prices/labels/tickets.

When interviewed 6 months after their appointment with the ILVS, 93\% of patients had been prescribed an LVA. Approximately three quarters of interviewees stated that they had attempted using their prescribed LVAs for the following

Table 3 Age and sex of participants

\begin{tabular}{lc}
\hline Age (years) & No (\%) \\
\hline $34-55$ & $2(3)$ \\
$56-70$ & $14(19)$ \\
$71-85$ & $38(54)$ \\
86 and over & $17(24)$ \\
Sex & \\
Female & $49(69)$ \\
Male & $22(31)$ \\
Seen by ILVS before? & $16(22)$ \\
Yes & $55(78)$ \\
No & \\
Live alone? & $38(54)^{*}$ \\
Yes & $33(46)$ \\
No &
\end{tabular}

*37 patients (52\%) were living alone before their ILVS appointment and one patient's living arrangements had altered to living alone when followed up 6 months later. 


\begin{tabular}{|l|l|}
\hline \multicolumn{2}{l|}{ Table 4 Patients seen by ILVS before } \\
\hline No $(\%)$ \\
\hline Between 6 and 12 months & $6(38)$ \\
$1-2$ years & $4(24)$ \\
2 years & $6(38)$ \\
Total & $16(100)$ \\
\hline
\end{tabular}

activities: reading ordinary sized print reading materials, reading their own correspondence, and reading instructions on packets, tins and medicines (Table 6).

At least half of those patients had found the LVAs quite helpful for performing these tasks (Table 7).

All of the low vision patients with one exception had used the LVA that they had been prescribed by the ILVS for at least one of the 19 activities listed in this section of the questionnaire.

Over half of those interviewed stated that they used their preferred LVA for reading several times each day but 10 patients $(14 \%)$ never used their preferred LVA for reading (Table 8).

Approximately half of the patients used their preferred LVA to read for up to 30 minutes and a quarter of those interviewed were able to use their LVA for short periods of "spot reading" (Table 9).

\section{VISION RELATED QOL}

The results of the VCMI before and 6 months after contact with the ILVS are shown in Table 10. There was a statistically significant reduction in concern in three particular areas after contact with the ILVS: fear of deterioration of vision, safety at home, and coping with everyday life.

No statistically significant differences were found between baseline VCMI index scores of patients who had been seen by the ILVS before and those who had not (Table 11), or between those patients who lived alone and those who did not (Table 12).

\section{DISCUSSION}

While it would have been preferable to have interviewed only those patients who had never had contact with the ILVS before, this would have reduced the size of the study population and excluded many patients with more advanced eye disease. Of the $22 \%$ of participants who had had contact with the ILVS before this study, more than half had not been seen for at least a year, at a much earlier stage in the disease process. There was no statistically significant difference in vision related QOL as measured by baseline VCMl index scores between patients who had been seen by the ILVS before and those who had not at the start of the study.

It was felt that following up patients 6 months after contact with the ILVs would allow sufficient time for them to acquire the independent living skills which are an integral part of the rehabilitation process without a significant deterioration in their visual pathology. Patients were reinterviewed face to face rather than by telephone, which has been shown by the researchers who developed the VCMl to cause a general bias towards under-reporting. ${ }^{27}$

A "restrictions in activities of daily living" questionnaire ${ }^{24}$ was used to assess degree of difficulty patients experienced with task performance because of visual impairment. The majority of tasks with which patients reported most difficulty related to reading, which is consistent with the view that this is the principal handicap for most patients with visual impairment. ${ }^{8}$ However, the wide range of tasks attempted by most interviewees suggests that low vision rehabilitation should concentrate on improvement of all activities of daily living rather than simply sustained reading. Leat et $a l^{7}$ identify "survival or spot" reading tasks of limited duration as being vitally important to the visually impaired.

There was a significant increase in the number of patients who had read or tried to read ordinary print 6 months after their appointment with the ILVS compared with at their first

Table 5 During the past month have you done or attempted to do the following tasks

\begin{tabular}{|c|c|c|c|c|c|c|c|}
\hline & \multicolumn{2}{|l|}{ Yes } & \multicolumn{2}{|l|}{ No } & \multicolumn{2}{|c|}{ Missing } & \multirow{2}{*}{$\begin{array}{l}\text { p Values for } \\
\text { differences between } \\
\text { distributions }\end{array}$} \\
\hline & Initial & Follow up & Initial & Follow up & Initial & Follow up & \\
\hline $\begin{array}{l}\text { Read or tried to read ordinary print books/newsprint/ } \\
\text { magazines/TV times }\end{array}$ & 45 & 54 & 26 & 16 & 0 & 1 & $0.049^{*}$ \\
\hline $\begin{array}{l}\text { Read or tried to read large print books, large print } \\
\text { newspapers, or newspaper headlines }\end{array}$ & 48 & 37 & 20 & 34 & 3 & 0 & $0.015^{*}$ \\
\hline $\begin{array}{l}\text { Read or tried to read letters/cards/bank statements/other } \\
\text { correspondence }\end{array}$ & 59 & 54 & 12 & 17 & 0 & 0 & 0.332 \\
\hline Read or tried to read your own writing & 51 & 48 & 19 & 23 & 1 & 0 & 0.454 \\
\hline $\begin{array}{l}\text { Read or tried to read instructions on packets, tins, bottles, } \\
\text { medicines, etc }\end{array}$ & 55 & 57 & 16 & 14 & 0 & 0 & 0.791 \\
\hline Read or tried to read shop prices/labels/tickets & 49 & 34 & 22 & 37 & 0 & 0 & $0.001^{*}$ \\
\hline $\begin{array}{l}\text { Read or tried to read the markings on dials-eg, on the } \\
\text { cooker, radio, hi-fi, washing machine, etc }\end{array}$ & 59 & 54 & 12 & 17 & 0 & 0 & 0.302 \\
\hline $\begin{array}{l}\text { Read or tried to read the telephone directory to check } \\
\text { numbers }\end{array}$ & 21 & 25 & 49 & 45 & 1 & 1 & 0.344 \\
\hline Read or tried to read the time on your watch & 52 & 52 & 19 & 18 & 0 & 1 & 1.00 \\
\hline Tried to fill in forms, cheques, cards, etc & 42 & 33 & 29 & 38 & 0 & 0 & 0.108 \\
\hline Signed or tried to sign your own name & 69 & 67 & 2 & 4 & 0 & 0 & 0.5 \\
\hline Written or tried to write your own letters & 24 & 22 & 47 & 49 & 0 & 0 & 0.791 \\
\hline Identified or tried to identify money & 70 & 67 & 1 & 4 & 0 & 0 & 0.375 \\
\hline Sewed/knitted/mended or attempted to sew, knit, or mend & 16 & 20 & 55 & 51 & 0 & 0 & 0.344 \\
\hline Done or tried to do a special hobby & 11 & 14 & 57 & 57 & 3 & 0 & 1.000 \\
\hline Carried out or attempted to carry out DIY/repairs/fix things & 16 & 10 & 54 & 61 & 1 & 0 & 0.210 \\
\hline Watched or attempted to watch TV & 68 & 70 & 3 & 1 & 0 & 0 & 0.500 \\
\hline $\begin{array}{l}\text { Read or attempted to read street signs/bus numbers/ } \\
\text { directions, etc }\end{array}$ & 39 & 34 & 32 & 37 & 0 & 0 & 0.302 \\
\hline Been on a trip or special day out & 39 & 40 & 32 & 31 & 0 & 0 & 1.000 \\
\hline
\end{tabular}


Table 6 Have you tried using your magnifier(s) for this?

\begin{tabular}{|c|c|c|c|c|c|c|}
\hline & \multicolumn{2}{|l|}{ Yes } & \multicolumn{2}{|l|}{ No } & \multicolumn{2}{|c|}{ Missing } \\
\hline & No & $\%$ & No & $\%$ & No & $\%$ \\
\hline $\begin{array}{l}\text { During the past month, have you: } \\
\text { Read or tried to read ordinary print books/newsprint/magazines/TV times } \\
\text { Read or tried to read large print books, large print newspapers, or newspaper headlines } \\
\text { Read or tried to read letters/cards/bank statements/other correspondence } \\
\text { Read or tried to read your own writing } \\
\text { Read or tried to read instructions on packets, tins, bottles, medicines, etc } \\
\text { Read or tried to read shop prices/labels/tickets } \\
\text { Read or tried to read the markings on dials-eg, on the cooker, radio, hi-fi, washing machine, etc } \\
\text { Read or tried to read the telephone directory to check numbers } \\
\text { Read or tried to read the time on your watch } \\
\text { Tried to fill in forms, cheques, cards, etc } \\
\text { Signed or tried to sign your own name } \\
\text { Written or tried to write your own letters } \\
\text { Identified or tried to identify money } \\
\text { Sewed/knitted/mended or attempted to sew, knit, or mend } \\
\text { Done or tried to do a special hobby } \\
\text { Carried out or attempted to carry out DIY/repairs/fix things } \\
\text { Watched or attempted to watch TV } \\
\text { Read or attempted to read street signs/bus numbers/directions, etc } \\
\text { Been on a trip or special day out }\end{array}$ & $\begin{array}{r}53 \\
22 \\
51 \\
24 \\
51 \\
22 \\
18 \\
25 \\
6 \\
24 \\
11 \\
7 \\
13 \\
9 \\
3 \\
2 \\
8 \\
2 \\
7\end{array}$ & $\begin{array}{r}75 \\
31 \\
72 \\
34 \\
72 \\
31 \\
25 \\
35 \\
9 \\
34 \\
16 \\
10 \\
18 \\
13 \\
4 \\
3 \\
11 \\
3 \\
10\end{array}$ & $\begin{array}{l}14 \\
35 \\
15 \\
39 \\
17 \\
32 \\
50 \\
40 \\
57 \\
41 \\
57 \\
55 \\
55 \\
54 \\
46 \\
45 \\
57 \\
56 \\
51\end{array}$ & $\begin{array}{l}20 \\
49 \\
21 \\
55 \\
24 \\
45 \\
70 \\
56 \\
80 \\
58 \\
80 \\
78 \\
78 \\
76 \\
65 \\
63 \\
80 \\
79 \\
72\end{array}$ & $\begin{array}{r}4 \\
14 \\
5 \\
8 \\
3 \\
17 \\
3 \\
6 \\
8 \\
6 \\
3 \\
9 \\
3 \\
8 \\
22 \\
24 \\
6 \\
13 \\
13\end{array}$ & $\begin{array}{r}6 \\
20 \\
7 \\
11 \\
4 \\
24 \\
4 \\
9 \\
11 \\
9 \\
4 \\
13 \\
4 \\
11 \\
31 \\
34 \\
9 \\
18 \\
18\end{array}$ \\
\hline
\end{tabular}

Table 7 If you have tried to use your magnifier(s) for this how helpful have you found them?

\begin{tabular}{|c|c|c|c|}
\hline & $\begin{array}{l}\text { Extremely/ } \\
\text { moderately } \\
\text { helpful (n) }\end{array}$ & $\begin{array}{l}\text { Slightly/not at all } \\
\text { helpful (n) }\end{array}$ & Total (n) \\
\hline \multicolumn{4}{|l|}{ During the past month, have you: } \\
\hline Read or tried to read ordinary print books/newsprint/magazines/TV times & 38 & 15 & 53 \\
\hline Read or tried to read large print books, large print newspapers or newspaper headlines & 12 & 10 & 22 \\
\hline Read or tried to read letters/cards/bank statements/other correspondence & 37 & 14 & 51 \\
\hline Read or tried to read your own writing & 15 & 9 & 24 \\
\hline Read or tried to read instructions on packets, tins, bottles, medicines, etc & 29 & 22 & 51 \\
\hline Read or tried to read shop prices/labels/tickets & 13 & 9 & 22 \\
\hline Read or tried to read the markings on dials - eg, on the cooker, radio, hi-fi, washing machine, etc & 6 & 12 & 18 \\
\hline Read or tried to read the telephone directory to check numbers & 12 & 13 & 25 \\
\hline Read or tried to read the time on your watch & 2 & 4 & 6 \\
\hline Tried to fill in forms, cheques, cards, etc & 12 & 12 & 24 \\
\hline Signed or tried to sign your own name & 5 & 6 & 11 \\
\hline Written or tried to write your own letters & 4 & 3 & 7 \\
\hline Identified or tried to identify money & 5 & 8 & 13 \\
\hline Sewed/knitted/mended or attempted to sew, knit or mend & 6 & 3 & 9 \\
\hline Done or tried to do a special hobby & 0 & 3 & 3 \\
\hline Carried out or attempted to carry out DIY/repairs/fix things & 1 & 1 & 2 \\
\hline Watched or attempted to watch TV & 4 & 4 & 8 \\
\hline Read or attempted to read street signs/bus numbers/directions, etc & 0 & 2 & 2 \\
\hline Been on a trip or special day out & 5 & 2 & 7 \\
\hline
\end{tabular}

interview. This was paralleled by a significant decrease in the number of respondents who had read large print, which implies that patients were using their LVAs successfully.

The mean patient index scores for vision related QOL issues indicated that the area of least concern for patients was safety within their own home and items provoking greatest concern were frustration and annoyance because of their poor sight and inability to carry out preferred activities. The use of a single index score has been recommended in QOL assessment, ${ }^{28}$ although such scores are inevitably associated with a loss of information about more specific issues. The VCMl score estimates patients' degree of overall concern but does not determine the cause of concern. However, some causes may be highly specific to individual patients or may concern issues which escape inclusion in even longer questionnaires.

Comparison of the baseline VCMI index score recorded for each patient in this study with a score generated 6 months after the patient's encounter with the ILVS provided a useful measure of any changes in vision related QOL. The mean index scores for eight of the 10 categories were lower when patients were re-interviewed; the exceptions were feelings of loneliness and isolation and inability to carry out preferred activities because of poor eyesight. This resulted in a statistically significant decrease in total mean index score 5 months after contact with the ILVS, indicating a reduction in patients' overall degree of concern. There was a statistically significant reduction in concern in three particular areas after contact with the ILVS: fear of deterioration of vision, safety at home, and coping with everyday life.

Patients were given information about their eye condition and visual prognosis by ILVS staff. ARMD is the most common diagnosis of patients attending ILVS clinics; 69\% of the study group had this condition. The knowledge that ARMD causes central visual loss and not total blindness is reassuring for ARMD sufferers. It is also likely that rehabilitation support including optical and non-optical LVAs could result in patients feeling safer at home and able 
Table 8 How often do you use your preferred LVA for reading?

\begin{tabular}{lrr}
\hline & No & $\%$ \\
\hline Several times each day & 36 & 51 \\
Once each day & 7 & 10 \\
A few times each week & 3 & 4 \\
Once each week & 6 & 9 \\
Rarely & 4 & 6 \\
Never & 10 & 14 \\
No answer & 5 & 7 \\
Total & 71 & 100 \\
\hline
\end{tabular}

Table 9 How long can your preferred LVA be used at any one time for reading?

\begin{tabular}{lrr}
\hline & No & $\%$ \\
\hline Less than 1 minute & 2 & 3 \\
$1-5$ minutes & 17 & 24 \\
$6-10$ minutes & 12 & 17 \\
$11-30$ minutes & 15 & 21 \\
More than 30 minutes & 9 & 13 \\
Not applicable & 3 & 4 \\
No answer & 13 & 18 \\
Total & 71 & 100 \\
\hline
\end{tabular}

to cope better with everyday activities. The fact that patients may have had time to accept the deterioration in their vision during the 6 month period between the two interviews may be reflected in how they rated their visually related QOL. However, this could have been offset by the fact that many of the patients are likely to have experienced a worsening of their vision over the 6 month period.

Approximately half of those patients who participated in the study lived alone. Many interviewees commented that they felt lonely and isolated because of their poor vision but were afraid of leaving the familiar environment of their home to venture outside. However, no statistically significant differences were found between VCMI index scores of patients living alone compared with those who lived with their spouse or other family members. This suggests that feelings of loneliness and isolation were not restricted to those participants who lived alone.
Table 11 Mean baseline VCM1 index scores for patients seen by ILVS before compared with those of patients not seen before

\begin{tabular}{llll}
\hline & $\begin{array}{l}\text { Patients } \\
\text { who had } \\
\text { been seen by not seen by } \\
\text { ILVS before } \\
\text { (n=55) }\end{array}$ & $\begin{array}{l}\text { Patients } \\
\text { ILV before } \\
(\mathbf{n}=16)\end{array}$ & $\begin{array}{l}\text { p Values for } \\
\text { differences } \\
\text { between } \\
\text { distributions }\end{array}$ \\
\hline $\begin{array}{l}\text { Mean baseline } \\
\text { VCM1 score }\end{array}$ & 2.0 & 2.1 & 0.2347 \\
\hline
\end{tabular}

The concerns which were least affected by contact with the service were inability to carry out preferred activities because of failing vision and feelings of loneliness and isolation. In a study undertaken with partially sighted and blind people in 1998, loneliness was also identified as a particular problem. ${ }^{29}$ In response to the findings of this study we have made social isolation a strategic priority for the ILVS and are arranging appropriate training for social services staff and volunteers to try to address the situation. Many rehabilitation services have reduced their emphasis on this area in favour of other aspects of rehabilitation. Our study would indicate that social isolation must now more than ever be tackled by services for people with low vision.

An example of a scheme already initiated by the ILVS is a new service whereby a group of volunteers offer "telecare" to clients who live alone. The volunteers make regular telephone calls to clients and are trained to pick up on key words that might suggest a change in circumstances. They can then refer relevant issues to professional staff.

This study highlighted the reading of packet instructions and medicine labels as a cause for frustration. The difficulty patients experience in reading medicine labels has been brought to the attention of the chief pharmacist in the area.

Since November 2000, the ILVS clinics have been held in a new sensory impairment centre where many agencies, including the local society for people with visual impairment, the deaf communication and audiology services, the Royal National Institute for the Blind, and several volunteer groups are based. The low vision clinic team now includes visually impaired volunteers who informally give information and support to patients attending the clinics. The greater

\begin{tabular}{|c|c|c|c|}
\hline & $\begin{array}{l}\text { Mean scores for } \\
\text { VCM } 1 \text { before } \\
\text { contact with } \\
\text { ILVS }(n=71)\end{array}$ & $\begin{array}{l}\text { Mean scores for } \\
\text { VCM1 } 6 \text { months } \\
\text { after contact with } \\
\text { ILVS }(n=71 \text { ) }\end{array}$ & $\begin{array}{l}\mathrm{p} \text { Values for } \\
\text { differences } \\
\text { between } \\
\text { distributions }\end{array}$ \\
\hline Have you felt embarrassed because of your eyesight? & 1.7 & 1.5 & 0.2749 \\
\hline $\begin{array}{l}\text { Have you felt frustrated or annoyed because of your } \\
\text { eyesight? }\end{array}$ & 3.0 & 2.9 & 0.4588 \\
\hline Have you felt lonely or isolated because of your eyesight? & 1.3 & 1.5 & 0.2733 \\
\hline Have you felt sad or low because of your eyesight? & 1.9 & 1.5 & 0.0791 \\
\hline Have you worried about your eyesight getting worse? & 2.9 & 2.1 & $0.0004^{*}$ \\
\hline $\begin{array}{l}\text { How offen has your eyesight made you concerned or } \\
\text { worried about your general safety at home? }\end{array}$ & 1.2 & 0.5 & $0.0005^{*}$ \\
\hline $\begin{array}{l}\text { How often has your eyesight made you concerned or } \\
\text { worried about your general safety when out of your home? }\end{array}$ & 2.3 & 2.0 & 0.3714 \\
\hline $\begin{array}{l}\text { How often has your eyesight made you concerned or } \\
\text { worried about coping with everyday life? }\end{array}$ & 1.6 & 1.2 & $0.0095^{*}$ \\
\hline $\begin{array}{l}\text { How often has your eyesight stopped you doing the } \\
\text { things you want to do? }\end{array}$ & 3.0 & 3.0 & 0.8696 \\
\hline $\begin{array}{l}\text { How much has your eyesight interfered with your life in } \\
\text { general? }\end{array}$ & 2.8 & 2.7 & 0.4544 \\
\hline Average index score & 2.2 & 1.8 & $0.0061^{*}$ \\
\hline
\end{tabular}


Table 12 Mean baseline VCM1 index scores for patients living alone compared with those who did not live alone

\begin{tabular}{llll}
\hline & $\begin{array}{l}\text { Patients who } \\
\text { lived alone } \\
(\mathbf{n}=37)\end{array}$ & $\begin{array}{l}\text { who did not } \\
\text { live alone } \\
(\mathbf{n}=34)\end{array}$ & $\begin{array}{l}\text { P Values for } \\
\text { differences } \\
\text { between } \\
\text { distributions }\end{array}$ \\
\hline $\begin{array}{l}\text { Mean baseline } \\
\text { VCM1 score }\end{array}$ & 2.1 & 2.1 & 0.7253 \\
\hline
\end{tabular}

collaboration now possible between the ILVS and the other agencies should improve support to people with low vision.

\section{ACKNOWLEDGEMENTS}

We would like to thank all of the staff of the Fife Low Vision clinics and Fife Society for the Blind for their cooperation throughout this study. Grateful thanks to all of the patients who took part in the study.

\section{Authors' affiliations}

A Hinds, Public Health Department, Fife NHS Board, Fife, UK

A Sinclair, J Park, H Paterson, M Macdonald, Fife Acute Hospitals Trust, Fife, UK

A Suttie, Fife Society for the Blind, Fife, UK

Part of this paper was presented at the International Conference on Low Vision, New York, 1999.

Funding: Grants from Royal College of Surgeons of Edinburgh and financial support from the Royal Blind Asylum and School.

Proprietary interests: none.

\section{REFERENCES}

1 Bruce I, McKennell A, Walker E. Blind and partially sighted adults in Britain: the RNIB survey. London: HMSO, 1991.

2 Dodds A. The psychology of rehabilitation. British Journal of Visual Impairment 1991;9:38-40.

3 Baker M, Winyard S. Lost vision: older visually impaired people in the UK. London: RNIB, 1998.

4 Stuck A, Walthert J, Nikolas T, et al. Risk factors for functional status decline in community living elderly people: a systematic literature review. Soc Sci Med 1999:48:445-69.

5 Rudberg M, Furner S, Dunn J, et al. The relationship of visual and hearing impairments to disability: an analysis using the longitudinal study of ageing J Gerontol 1993;48:M261-5.

6 Fielder A, Bentley C, Moseley, M. Recent advances: ophthalmology. BMJ 1999;318:717-20.
7 Leat S, Fryer A, Rumney N. Outcome of low vision aid provision: the effectiveness of a low vision clinic. Optom Vis Sci 1994;71:199-206.

8 Rumney N. An optometric approach to low vision services. Br J Vis Impair 1982;10:89-92.

9 Ryan B, Culham L. Fragmented vision: survey of low vision in the UK. London: RNIB, 1999.

10 Culham LE, Ryan B, Jackson AJ. Low vision services for vision rehabilitation in the United Kingdom. Br J Ophthalmol 2002;86:743-7.

11 Ryan B, McCloughan L. Our better vision. What people need from low vision services in the UK. London: RNIB, 1999.

12 Royal College of Ophthalmologists. The provision of low vision care. London: RCO, 1998.

13 Sinclair A, Grimsley A, Horobin J. The interdisciplinary approach to low vision services-how does it work? Vision rehabilitation: assessment, intervention and outcomes. Vision rehabilitation: assessment, intervention and outcomes. Selected papers from the International Conference on Low Vision, July 1999.

14 Ferrier C. Provision and training in the use of low vision aids by optometrists in Fife, audit report, Edinburgh: Fife Health Board report, 1997.

15 Scott I, Schein O, West S. Functional status and quality of life measurement among ophthalmic patients. Arch Ophthalmol 1994;112:329-35.

16 Brenner $M$, Curbow B, Legro $M$. The proximal-distal continuum of multiple health outcome measures. Med Care 1995;33:AS236-44.

17 Parrish RK, Gedde SJ, Scott IU. Visual function and quality of life among patients with glaucoma. Arch Ophthalmol 1997;115:1447-55

18 Williams R, Brody B, Thomas R. The psychosocial impact of macular degeneration. Arch Ophthalmol 1998;1 16:514-20.

19 Bullimore M, Raasch G, Cutter G. Quality of life assessment in a low vision population. Invest Ophthalmol Vis Sci 1997;38:A3288.

20 Margolis MK, Coyne K, Kennedy-Martin T. Vision-specific instruments for the assessment of health-related quality of life and visual functioning. Pharmacoeconomics 2002;20:791-812.

21 Hart PM, Chakravarthy U, Stevenson MR. A vision specific functional index for use in patients with age-related macular degeneration. $\mathrm{Br} J$ Ophthalmol 1999;83:1115-20.

22 Mangione CM, Lee PP, Pitts J. Psychometric properties of the National Institute Visual Function questionnaire (NEI-VFQ). Arch Ophthalmol 1998; 116:1496-504.

23 Frost NA, Sparrow JM, Durant JS. Development of a questionnaire from measurement of vision-related quality of life. Ophthalmic Epidemiol 1998;5:185-210.

24 Russell W, Harper R. Randomised controlled trial of an integrated versus an optometric low vision rehabilitation service for patients with age-related macular degeneration. Optom Vis Sci 1997;74:12S

25 Hazel CA, Petre KL, Armstrong RA, et al. Visual function and subjective quality of life compared in subjects with acquired macular disease. Invest Ophthalmol Vis Sci 2000:41:1309-15.

26 Russell W, Harper R, Reeves B, et al. Randomised controlled trial of an integrated versus an optometric low vision rehabilitation service for patients with age-related macular degeneration: study design and methodology. Ophthal Physiol Opt 2001;21:36-44.

27 Frost NA, Sparrow JM, Hopper CD. Reliability of the VCM1 Questionnaire when administered by post and by telephone. Ophthalmic Epidemiol 2001;8:1-11.

28 Gill T, Feinstein A. A critical appraisal of the quality of quality of life measurements. JAMA 1994;272:619-26.

29 Smeeth L, lliffe S. Effectiveness of screening older people for impaired vision in a community setting: systematic review of evidence from randomised controlled trials. BMJ 1998;316:660-3. 